\title{
Recombinant Human Serum Amyloid P/Pentraxin 2
}

National Cancer Institute

\section{Source}

National Cancer Institute. Recombinant Human Serum Amyloid P/Pentraxin 2. NCI

Thesaurus. Code C113177.

A fully recombinant form of the human pentraxin 2 (PTX2) protein with potential antifibrotic activity. Upon intravenous administration, recombinant human serum amyloid P/pentraxin 2 (PRM-151) may inhibit myofibroblast generation by preventing the differentiation of circulating monocytes into fibrocytes and profibrotic macrophages. PTX2 is a circulating plasma protein that belongs to the class of pattern recognition receptors (PRR) of the innate immune system. 